\title{
ON THE DESIRABILITY OF TAXING CHARITABLE CONTRIBUTIONS
}

\author{
TOMER BLUMKIN \\ EFRAIM SADKA
}

CESIFO WORKING PAPER No. 1900

CAtegory 1: Public Finance

JANUARY 2007

An electronic version of the paper may be downloaded

- from the SSRN website:

- from the RePEc website:

www.SSRN.com

www.RePEc.org

- from the CESifo website: www.CESifo-group.de 


\title{
ON THE DESIRABILITY OF TAXING CHARITABLE CONTRIBUTIONS
}

\begin{abstract}
We develop a model that allows for public goods and status signaling through charitable contributions. This model provides a unified framework in which contributions are driven both by altruism and status signaling. We use this setup to re-examine the conventional practice of rendering a favorable tax treatment to charitable contributions.

JEL Code: H2, D6.

Keywords: optimal taxation, re-distribution, charitable contributions, inequality.

\author{
Tomer Blumkin \\ Department of Economics \\ Ben-Gurion University \\ Beer-Sheba 84105 \\ Israel \\ tomerblu@bgumail.bgu.ac.il
}

\author{
Efraim Sadka \\ The Eitan Berglas School of Economics \\ Tel Aviv University \\ Tel-Aviv 69978 \\ Israel \\ sadka@post.tau.ac.il
}

December 2006 


\section{Introduction}

According to an annual survey, Giving USA, total charitable giving in America in 2004 amounted to \$ 249 billion, over 2 percent of GDP. This outstanding figure reflects, in part, a response to what has been a consistent policy of US government since 1917 to grant favorable tax treatment to charitable contributions in order to promote philanthropy. Charitable contributions are accorded favorable tax treatment elsewhere too. This favorable treatment takes a variety of forms, including tax deductions or tax credits.

From a public economics point of view, a key reason for subsidizing charitable contributions derives from a Pigouvian motive. Looking at private charity as a voluntary mechanism for the provision of public goods implies that in the absence of intervention, individuals tend to overlook the positive externality their contributions exert on the rest of the community (the classical free-rider problem). This will be the case even when individuals derive utility from the act of giving itself, which provides them with an extra incentive to donate ['warm glow' approach as in Andreoni (1989, 1990)]. Recently, Diamond (2006) provides a novel argument in favor of the conventional wisdom about subsidizing charitable contributions. He points out that subsidizing private donations may mitigate the incentive constraints associated with income taxation, thereby allowing the government to attain further redistribution.

De-Botton (2005) points out that in a modern society, individuals' concerns about how they are being perceived by others have evolved to a level of anxiety. Following the work of Frank (1984a, 1984b, 1985a and 1985b) on the demand for status, there seems to be another motive for contributing; namely, the desire to demonstrate wealth. While there are other means to signal status, notably through 
conspicuous consumption of private goods ${ }^{1}$, Glazer and Konrad (1996) explain that there are good reasons to believe in a strong signaling motive for charity. They argue that conspicuous consumption, unlike charity, may be banned by social norms. They also point out that ownership of luxury goods may be difficult to observe reliably. In contrast, donations can prove very effective in conveying signals to individuals belonging to a peer group, who can not observe the big house or the luxury car (such as the case of distant college roommates who read the alma mater's alumni magazine and notice the recent contribution of their peers.).

Glazer and Konrad (1996) cite empirical evidence in support of the hypothesis that donations are not purely driven by altruistic motives. One such evidence is that only a tiny fraction of donations is given anonymously. For instance, the fall 1991 Yale Law Report, sent to the alumni of the Yale Law School, indicates that only 4 out of 1950 donors were anonymous. Furthermore, when donations are reported in broad categories, rather than the exact amounts given, people tend to 'converge' to the lower limit of the specified category. For instance, the 1993-4 report of the Harvard LawSchool Fund indicates that contributions of exactly \$500 constitute 93 percent of total amount raised in the category $\$ 500-\$ 999$.

Harbaugh (1998b) employs a theoretical model of the donor's optimization problem in Harbaugh (1998a), and uses data on reported donations of a prestigious law school alumni from the same cohort, to identify the status effect associated with donations ("prestige motive"). His estimation results indicate that many donors would more that double their donations in response to the prestige motive. ${ }^{2}$

\footnotetext{
${ }^{1}$ Hirsch (1976) refers to those consumption goods used to signal status as 'positional goods'.

2 Notably, a change in the category reporting plan of the university, which occurred during the period examined, resulted in a reduction in the number of donations at the omitted categories. This result is consistent with a prestige motive hypothesis.
} 
The existence of a strong status-signaling motive for contributions alongside the altruistic one has two implications for the design of the tax treatment of charitable giving. First, on efficiency grounds, there is a case for taxing contributions as a means to internalize the negative externality associated with status acquisition Second, on equity grounds, a signaling motive renders charitable contributions an extremely efficient 'tagging device' [as in Akerlof (1978)] of the high-ability individuals who seek to signal their social status. ${ }^{3}$ This may call for taxing contributions as a supplement to the labor income tax system in order to attain enhanced re-distribution.

Status effects have been examined by the labor income tax literature. Boskin and Sheshinski (1978) is an early study that incorporates status in the design of the optimal income tax. They employ a model in which individuals care not only about their absolute income level but rather also about their relative income level. However, they analyze only the externality effect of status, as individuals do not engage in signaling in their model. More recently, Ireland (1998 and 2001) employs a model in which individuals signal their social status through consumption choices. He focuses on the design of the income tax schedule and rules out the possibility of direct taxing of the consumption signals. ${ }^{4}$ In the present study we develop a model that allows for public goods and status signaling through charitable contributions. This model provides a unified framework in which contributions are driven both by altruism and status signaling. We use this setup to re-examine the conventional practice of rendering a favorable tax treatment to charitable contributions.

\footnotetext{
3 A recent survey of Philanthropy by The Economist (February, 2006) cites a study by Schervish of Boston College, showing that American Families with a net worth of 1 million dollars or more, accounted for 4.9 percent of the total number of donations to charitable organizations in 1997, but as much as 42 percent of the value.

${ }^{4}$ See Ireland (2001) for discussion of the difficulty of directly taxing consumption signals.
} 
The organization of the paper is as follows. Section 2 introduces the basic framework. In section 3 we characterize the equilibrium. The succeeding section examines the optimal tax treatment of charitable contributions. Section 5 concludes.

\section{The Model}

Consider an economy with a continuum of individuals (whose number is normalized to one), producing a single consumption-good. Following Mirrlees (1971) we assume that individuals differ in their innate ability denoted by $w$ (which also denotes the hourly wage rate in the competitive labor market). The productiontechnology employs labor only and exhibits constant returns to scale and perfect substitutability among various skill levels. We further assume that the innate ability is distributed according to some cumulative distribution function $F(w)$ with the support $-[\underline{w}, \bar{w}]$.

As in Mirrlees (1971), all individuals share the same preferences, which are represented by the following utility function:

$$
U(c, l, z, g)=\beta \cdot p(z) \cdot b+u(c)+h(l)+(1-\beta) \cdot v(z)+\alpha \cdot r(g),
$$

where $c$ denotes consumption, $l$ denotes leisure, $z$ denotes charitable contribution and $g$ denotes public good provision; the functions $u, h, v$ and $r$ are assumed to be strictly concave and strictly increasing; $b>0, \alpha>0$ and $0 \leq \beta \leq 1$.

The utility specification given in (1) captures the two contribution motives discussed in the introduction. The altruistic motive is captured by the function $v$ which measures the joy of giving ('warm glow' effect). The strategic motive to signal ability and thereby gain social status was first investigated by Glazer and Konrad (1996). In our framework it is captured by the first term on the right-hand side of equation (1). To see this observe that for analytical tractability we assume a two (status) class 
society (while a continuum of abilities); in such a society individuals gain social status if they credibly signal that their ability (the only source of heterogeneity in the economy) exceeds a certain threshold, denoted by $\hat{w} .^{5}$ We emphasize that this threshold is exogenously given. Denoting by $\widetilde{w}$ the perceived ability of an individual in equilibrium, we denote by $p(z)$ the probability that the individual's perceived ability exceeds the threshold $\hat{w}$, conditional on the fact that the individual has contributed $z$. Formally,

(2) $\quad p(z)=\operatorname{Pr}[\tilde{w} \geq \hat{w} \mid z]$.

The parameter $b$ captures the gain from social status. The product $p(z) \cdot b$ thus measures the expected gains from status. ${ }^{6}$ Note crucially that the status-signaling activity per se (that is, apart from its direct contribution to public good provision and to the joy of giving) is wasteful, because it does not add anything to total social welfare; for an elaborate discussion see section 4.2.

The parameter $\beta$ measures the relative importance of each contribution motive. When $\beta=0$, contribution is purely altruistic, whereas when $\beta=1$, contribution is driven only by status seeking.

Several remarks are in order regarding the utility specification we have chosen. First, note that contributions finance a general pure public good. This is a simplifying assumption, as in reality many contributions finance local public (possibly congestible) goods; dropping out this assumption will not change the qualitative nature of the analysis. Note also that we make a 'large economy assumption' by letting the amount of public good provision, $g$, be a fixed parameter from the point of view of the individual (not depending on each individual's z). For

\footnotetext{
${ }^{5}$ Note that while there are only two status classes, there is nevertheless a continuum of abilities. Thus, our model is not restrictive for redistribution purposes.

${ }^{6}$ It is assumed that consumption and leisure choices of an individual are not observed (or cannot be verified) by other individuals. Thus, charitable contribution is the only signal observed.
} 
most people this would reflect reality, whereas for the very rich individuals this might be violated. However, this assumption may reflect also the fact that contributors often gain very little from the projects financed by their own donations. ${ }^{7}$ The parameter $\alpha>0$ represents the intensity of the preference for the public good (relative to other goods).

We assume that a linear labor income tax system is in place, where the marginal tax rate is denoted by $t$, and the uniform lump-sum transfer (possibly negative) is given by $T$. We further assume that a tax (s) on charitable contributions (possibly negative, that is a subsidy) may be levied. Note that allowing individuals to deduct their charitable contributions from their taxable incomes, or, granting them tax credits, amounts to such a subsidy. We turn next to characterize the equilibrium for the signaling game.

\section{Equilibrium}

For tractability, we follow Glazer and Konrad (1996) and Ireland (1994 and 2001) in restricting attention to the separating fully revealing equilibrium, which in our framework implies that all individuals (and only those) with ability (weakly) exceeding the threshold $\hat{w}$ signal their ability and enjoy the respective social status. This equilibrium is defined by a threshold level of contributions, $\hat{z}>0$, and a probability function $p(z)$, such that:

(i) $\quad p(z)= \begin{cases}1 & \mathrm{z} \geq \hat{\mathrm{z}} \\ 0 & \mathrm{z}<\hat{\mathrm{z}}\end{cases}$

\footnotetext{
${ }^{7}$ Relaxing this assumption will not alter the gist of our analysis. An alternative assumption concerning the provision of public good is that each individual has a positive (that is, non-atomistic) mass; see, for instance, Green and Laffont (1979) and Bergstrom, Blume and Varian (1986). The latter assumption may be particularly relevant in the context of local public goods.
} 
(ii) Given the probability function $p(z)$, all individual whose innate ability is exceeding $\hat{w}$ choose to contribute an amount $z \geq \hat{z}$, whereas all other individuals optimally set their contribution at a level $z<\hat{z}$. We emphasize that $\hat{z}$ is endogenously determined (in equilibrium). Each individual who donates an amount exceeding $\hat{z}$ credibly signals that her innate ability is above the exogenously given $\hat{w}$, and hence derives a status gain.

Each individual has to decide on the levels of consumption, leisure and charitable contribution, given the function $p(z)$, so as to maximize the utility subject to the budget constraint:

$$
(1-t) \cdot w \cdot(1-l)+T \geq c+(1+s) \cdot z
$$

We turn next to study the solution for the consumer optimization problem. Denote it by $c^{*}(w), l^{*}(w)$ and $z^{*}(w)$, where the tax parameters are henceforth omitted to abbreviate the notation. Similarly, we denote by $V^{*}(w)$ the maximized level of utility.

We can describe the individual decision as a two-stage process. First, she ignores the signaling motive and respective status benefit [that is, ignoring the term $\beta \cdot p(z) \cdot b$ in the utility function (1)], and chooses $c, l$ and $z$ so as to maximize the utility function (1) subject to the budget constraint (3). This is a standard utility maximization problem. We denote by $c^{N S}(w), l^{N S}(w)$ and $z^{N S}(w)$, the optimal choices of consumption, leisure and charitable contribution, respectively, for an individual of ability $w$ in this case, where the superscript NS stands for 'no-signaling'. Similarly, denote the corresponding value of the maximized utility by $V^{N S}(w)$. Now, in the second stage, we reinstate the signaling benefit term, $\beta \cdot p(z) \cdot b$, and ask whether and how her choices in the first stage will be altered. There are two cases to consider. 
Consider first an individual who chose in the first stage to contribute an amount (weakly) exceeding the threshold $\hat{z}$, that is an individual with innate ability $w$ for which $z^{N S}(w) \geq \hat{z}$. For this individual, the term $\beta \cdot p(z) \cdot b$ is a constant added to the utility function. Thus, there will be no change in behavior, that is: $c^{*}(w)=c^{N S}(w), l^{*}(w)=l^{N S}(w)$ and $z^{*}(w)=z^{N S}(w)$.

Consider next an individual who chose in the first stage to make a contribution below the threshold $\hat{z}$. Such an individual now has the option to increase her contribution to a level equaling or exceeding $\hat{z}$ and enjoy the status benefit of $\beta \cdot b$ (recalling that $p(\mathrm{z})=1$ in this case). Imagine such an individual as maximizing her utility in (1), with the term $\beta \cdot b$, subject to the budget constraint (3), and an additional (signaling) constraint:

(4) $\quad z \geq \hat{z}$.

We denote by $c^{S}(w), l^{S}(w)$ and $z^{S}(w)$, the optimal choices in this case of consumption, leisure and charitable contribution, respectively, for an individual of ability $w$, where the superscript $S$ stands for 'signaling'. Similarly, we denote by $V^{s}(w)$ the corresponding maximized level of utility. An individual with innate ability $w$ will choose to increase her contribution to $\hat{z}$ (but not beyond $\hat{z}$ - see below) if, and only if, $V^{S}(w) \geq V^{N S}(w)$.

In equilibrium the following condition has to be satisfied:

$$
V^{N S}(\hat{w})=V^{S}(\hat{w})
$$

In words, the individual with the ability level $\hat{w}$, the threshold ability above which individuals gain social status, has to be indifferent between signaling and not signaling. To see this, note that in a separating equilibrium, an individual with ability $\hat{w}$ will choose to signal. Thus, the term on the left-hand side of (5) should not exceed 
the term on the right-hand side. Suppose, by negation, that the inequality is strict, that is the individual strictly prefers to engage in signaling. By continuity considerations, an individual with ability slightly lower than $\hat{w}$ will then also choose to signal, which would violate the definition of our equilibrium. Thus, we obtain a contradiction. Clearly, the equality in (5) implies that the signaling constraint in (4) has to bind, which in turn implies that $z^{S}(\hat{w})=\hat{z}>z^{N S}(\hat{w})$. Mild parametric restrictions on the utility function in (1) guarantee the existence of a threshold level of contributions, $\hat{z}$, which satisfies the equality in (5). For example, when the functions $u, h$ and $v$ are logarithmic, it is straightforward to verify that the equality in (5) is satisfied. ${ }^{8}$ As $\partial V^{S}(\hat{w}) / \partial \hat{z}<0$ whereas by construction, $\partial V^{N S}(\hat{w}) / \partial \hat{z}=0$, there exists a unique value of $\hat{z}$ for which the equality in (5) is satisfied (for any given set of tax parameters). To establish the existence of an equilibrium, we need to verify that for any ability $w<\hat{w}$, individuals choose not to engage in signaling; whereas, for any ability level $w>\hat{w}$, individuals do engage in signaling. There are two cases to consider. Consider first the case where $z^{N S}(w) \geq \hat{z}$. In such a case, $V^{S}(w)>V^{N S}(w)$, by construction. By virtue of the strict concavity of the functions $u, h$ and $v$, charitable contribution, $z$, is a normal good; hence, as $\hat{z}>z^{N S}(\hat{w})$, this may only hold true for $w>\hat{w}$, which is consistent with the separating equilibrium presumption. Consider next the case where $z^{N S}(w)<\hat{z}$. In order to prove the result, it suffices to show that the following condition holds:

$$
\partial V^{S}(w) / \partial w-\partial V^{N S}(w) / \partial w \geq 0 .
$$

8 To see this, note, that when $\hat{z}=z^{N S}$, it follows that $V^{N S}(\hat{w})<V^{S}(\hat{w})$; whereas, when $\hat{z}=[w(1-t)+T] /(1+s)$, namely the individual spends her entire potential income on charitable contributions, consumption and leisure drop to zero, hence $V^{s}(\hat{w})=-\infty$, which obviously implies that $V^{N S}(\hat{w})>V^{S}(\hat{w})$. Existence follows by the intermediate value theorem. 
To see why the equality in (6) holds, note that, by employing the envelope theorem, the inequality in (6) implies:

$$
\lambda^{S}(w) \cdot(1-t) \cdot\left[1-l^{S}(w)\right]-\lambda^{N S}(w) \cdot(1-t) \cdot\left[1-l^{N S}(w)\right] \geq 0,
$$

where $\lambda^{S}$ and $\lambda^{N S}$ are, correspondingly, the Lagrange multipliers in the individual maximization for the 'signaling' and 'non-signaling' cases. By virtue of the strict concavity of the functions $u, h$ and $v$, both consumption, $c$, and leisure, $l$, are normal goods. Thus, $l^{S}<l^{N S}$ and $\lambda^{S}>\lambda^{N S}$ (as $c^{S}<c^{N S}$ ), which implies that the inequality in (7) is satisfied. This concludes the proof and the characterization of the equilibrium.

To summarize:

(8a) $\quad c^{*}(w)= \begin{cases}c^{S}(w) & \text { if } z^{N S}(w)<\hat{z} \text { and } w \geq \hat{w} \\ c^{N S}(w) & \text { otherwise }\end{cases}$

(8b) $\quad I^{*}(w)= \begin{cases}l^{S}(w) & \text { if } z^{N S}(w)<\hat{z} \text { and } w \geq \hat{w} \\ l^{N S}(w) & \text { otherwise }\end{cases}$

(8c) $\quad z^{*}(w)= \begin{cases}z^{S}(w) & \text { if } z^{N S}(w)<\hat{z} \text { and } w \geq \hat{w} \\ z^{N S}(w) & \text { otherwise }\end{cases}$

(8d) $\quad V^{*}(w)=\max \left\{V^{N S}(w), V^{S}(w)\right\}$

Note also that $\hat{z}$ itself is determined in equilibrium, so as to make all individuals (and only these individuals) with innate ability above the threshold $\hat{w}$ contribute an amount (weakly) exceeding $\hat{z}$. Formally $\hat{z}$ is defined implicitly by equation (5).

\section{The Tax-Treatment of Contributions}

The government is seeking to maximize some egalitarian social welfare function by choosing the fiscal instruments $t, T, s$ and $g$, subject to a revenue constraint, taking 
into account the optimal choices of the individuals. The egalitarian social welfare function is given by:

(9) $\quad W \equiv \int_{\underline{w}}^{\bar{w}} W[V(w)] d F(w)$,

where $W^{\prime}(V)>0$ and $W^{\prime \prime}(V)<0$. Naturally, the objective in (9) is maximized subject to the government revenue constraint,

$$
t \cdot \int_{\underline{w}}^{\bar{w}} w[1-l(w)] d F(w)+(1+s) \cdot \int_{\underline{w}}^{\bar{w}} z(w) d F(w)-g-T \geq 0 .
$$

There is another constraint, which requires that the government cannot confiscate the charitable contributions and direct them to its general needs (redistribution purposes in our case). Put differently, the level of public good provision should weakly exceed the total amount of contributions:

$$
g-\int_{\underline{w}}^{\bar{w}} z(w) d F(w) \geq 0
$$

To gain insight of the effect of status-seeking on the optimal tax treatment of contributions, we will begin our analysis in the absence of this effect and introduce it only later. That is, we first consider the case where contributions are driven entirely by altruism, namely $\beta=0$.

\subsection{The Case of Purely Altruistic Contributions}

We address the question of the desirability of levying a tax on (granting a subsidy to) charitable contributions, as a supplement to the optimal linear labor income tax system, when the contribution motive is purely altruistic. Starting from an optimal 
linear income tax system with zero tax on contributions $(s=0)$, we ask whether levying a small tax (possibly negative) on charitable contributions would increase welfare. ${ }^{9}$

Denote the Lagrangean expression for the optimal income tax problem, given a tax $s$ on contributions, by:

$$
\begin{aligned}
& L(s)=\int_{\underline{w}}^{\bar{w}} W\left[V^{N S}(w)\right] d F(w)+\mu_{1}\left\{t \cdot \int_{\underline{w}}^{\bar{w}} w\left[1-l^{N S}(w)\right] d F(w)+(1+s) \cdot \int_{\underline{w}}^{\bar{w}} z^{N S}(w) d F(w)-g-T\right\} \\
& +\mu_{2}\left\{g-\int_{\underline{w}}^{\bar{w}} z^{N S}(w) d F(w)\right\},
\end{aligned}
$$

where $\mu_{1}$ and $\mu_{2}$ denote the Lagrange multipliers associated with the constraints in equations (10) and (11). Employing the envelope theorem and omitting the NS superscript for brevity of notation, we seek to sign the following derivative:

$$
\begin{aligned}
\left.\frac{\partial L}{\partial s}\right|_{s=0, t^{*}, T^{*}, g^{*}}= & -\int_{\underline{w}}^{\bar{w}}\left[W^{\prime}[V(w)] \cdot \lambda(w) \cdot z(w)\right] d F(w)-\mu_{1} \cdot t \cdot \int_{\underline{w}}^{\bar{w}}\left[w \cdot \frac{\partial l(w)}{\partial s}\right] d F(w) \\
& +\mu_{1} \cdot \int_{\underline{w}}^{\bar{w}}[z(w)] d F(w)+\left(\mu_{1}-\mu_{2}\right) \cdot \int_{\underline{w}}^{\bar{w}}\left[\frac{\partial z(w)}{\partial s}\right] d F(w)
\end{aligned}
$$

where $t^{*}, T^{*}$ and $g^{*}$ denote the optimal tax parameters and $\lambda(w)$ denotes the Lagrange multiplier associated with the individual optimization.

There are two conflicting considerations in the design of the optimal tax/subsidy on charitable contributions. On the one hand, there is a Pigouvian motive to subsidize contributions, because they generate a positive externality. This is due to desirable. 
the fact that contributors fail to take into account the fact that any dollar contributed raises the well-being of other individuals as well (via increased provision of the public good). On the other hand, there is a re-distributive motive that calls for taxing contributions. To see this, note that in the presence of charitable contributions we have essentially two consumption goods: $c$ and $z$. Furthermore, $\mathrm{z}$ is a normal good (as shown above). Thus, a tax on contributions accompanied by an upward adjustment in the lump-sum transfer (to maintain the government revenue constraint) is progressive and therefore enhances re-distribution. As shown by Deaton (1979), when the utility function is both separable (between leisure and the set of consumption goods) and homothetic (with respect to the set of consumption goods), commodity taxation is redundant in the presence of an optimal linear labor income tax. Thus, there are no redistributive gains from taxing contributions in this case, and we are left with the Pigouvian motive, suggesting that charitable contributions should be subsidized. This establishes the following proposition (the proof is relegated to Appendix A):

Proposition 1: Suppose that the contribution motive is purely altruistic ( $\beta=0$ ), if the function $H(c, z) \equiv u(c)+v(z)$ is homothetic, the optimal tax on charitable contributions is negative.

This proposition justifies tax deductibility of or tax credits to charitable contributions when the latter are motivated purely by altruism. Naturally, this result extends also to the case where the altruistic motive is sufficiently strong relative to the status seeking motive (namely, for $\beta$ sufficiently small). Note, however, that in the absence of separability and homotheticity, the redistributive motive that may call for taxing charitable contributions (especially when charitable giving is a sort of a luxury good) could dominate the Pigouvian motive that calls for subsidizing such contributions, and a tax on charitable contributions may be called for. 
The case for subsidizing charitable contributions (allowing for tax deductions and/or credits) is further weakened when contributions are driven also by a status seeking motive. To demonstrate this argument in its sharpest relief, in the coming section we consider the extreme case where contributions are driven solely by the latter motive.

\subsection{The Case of Pure Status-Signaling}

We address the question of the desirability of levying a tax on charitable contributions, as a supplement to the optimal linear labor-income tax system, when the contribution motive is driven by pure status seeking, namely $\beta=1$. Note crucially that the status-signaling activity per-se (that is, apart from its direct contribution to the amount of the public good) is purely wasteful. In the absence of signaling all individuals would obtain the same average status, whereas with signaling some do gain high status and some gain no status, leaving the average level of status exactly at the same level as without signaling. We emphasize that the aggregate (average) amount of status is exogenously given, at the level of $[1-F(\hat{w})] \cdot b$. Thus, status signaling can only affect the distribution of this aggregate level of status. When no one signals (that is, in a pooling equilibrium) the expected value of status derived by each individual is given by the average level of status.

We re-formulate the Lagrangean for the case $\beta=1$, given a tax $s$ on contributions, to obtain: 


$$
\begin{aligned}
L(s) & =\int_{\underline{w}}^{\hat{w}} W\left[V^{N S}(w)\right] d F(w)+\int_{\hat{w}}^{\bar{w}} W\left[V^{S}(w)\right] d F(w) \\
& +\mu_{1}\left\{t \cdot\left[\int_{\underline{w}}^{\hat{w}} w\left[1-l^{N S}(w)\right] d F(w)+\int_{\hat{w}}^{\bar{w}} w\left[1-l^{S}(w)\right] d F(w)\right]+(1+s) \cdot \hat{z} \cdot[1-F(\hat{w})]-g-T\right\}+ \\
& \mu_{2}[g-\hat{z} \cdot[1-F(\hat{w})]]+\mu_{3}\left[V^{S}(\hat{w})-V^{N S}(\hat{w})\right],
\end{aligned}
$$

where $\mu_{i}, i=1,2,3$ denote the Lagrange multipliers, associated, respectively, with the revenue constraint given in equation (10), the public good provision constraint in equation (11) and the signaling constraint in equation (5). Clearly, in the case of pure status-signaling, only individuals whose innate ability exceeds the threshold, $\hat{w}$, engage in signaling via "charitable" contributions, and all of them will set their contributions at the level of $\hat{z}$. All other individuals will set their contributions at zero. This implies that the total amount of contributions is given by the term $\hat{z} \cdot[1-F(\hat{w})]$, which appears both in the revenue constraint and the public good provision constraint in the Lagrangean expression in (14). ${ }^{10}$

Starting from an optimal linear tax system with zero tax on contributions $(s=0)$, we examine the effect of a small tax on contributions. We seek to sign the following derivative (see appendix B for details):

$$
\begin{aligned}
\left.\frac{\partial L}{\partial s}\right|_{s=0, t^{*}, T^{*}, g^{*}, \hat{z}^{*}}= & -\hat{z} \cdot \int_{\hat{w}}^{\bar{w}}\left[W^{\prime}\left[V^{s}(w)\right] \cdot \lambda^{s}(w)\right] d F(w)-\mu_{1} \cdot t \cdot \int_{\hat{w}}^{\bar{w}}\left[w \cdot \frac{\partial l^{s}(w)}{\partial s}\right] d F(w) \\
& +\mu_{1} \cdot \hat{z} \cdot[1-F(\hat{w})]-\mu_{3} \cdot \lambda^{s}(\hat{w}) \cdot \hat{z}
\end{aligned}
$$

10 In this separating equilibrium all the individuals who signal, whose number is given by $1-F(\hat{w})$, obtain, each, a status level of $b$; all other individuals gain no status. The average level of status is given by $[1-F(\hat{w})] b$. 
Employing the first-order conditions for the optimal tax problem (see appendix C for details), we can re-write equation (15) as follows:

$$
\begin{aligned}
& \left.\frac{\partial L}{\partial s}\right|_{s=0, t^{*}, T^{*}, g^{*}, \hat{z}^{*}}=[\underbrace{\mu_{1} \cdot \hat{\mathrm{z}} \cdot[1-F(\hat{w})]-\hat{\mathrm{z}} \cdot \int_{\hat{w}}^{\bar{w}}\left[W^{\prime}\left[V^{S}(w)\right] \cdot \lambda^{S}(w)\right] d F(w)}_{\text {Redistributive Term }}] \\
& +[\underbrace{\hat{z} \cdot \int_{\hat{w}}^{\bar{w}}\left[W^{\prime}\left[V^{S}(w)\right] \cdot \lambda^{S}(w)\right] d F(w)}_{\text {Signaling Correction Term }}]+[\underbrace{-\left(\mu_{1}-\mu_{2}\right) \cdot \hat{z} \cdot[1-F(\hat{w})]}_{\text {Pigouvian Term }}] .
\end{aligned}
$$

Equation (16) decomposes the effect of a small tax on contributions into three terms. The first term on the right-hand side of equation (16) captures the redistributive effect of a unit increase in the tax on charitable contributions. To see this, note that the term $\hat{\mathrm{z}} \cdot[1-F(\hat{w})]$ is the additional amount of revenues raised by a unit increase in the tax on contributions (at $s=0$ ). Multiplying it by $\mu_{1}$, the marginal social benefit of a unit increase in the transfer $(T)$, yields the effect of the extra revenues on social welfare. As the burden of this unit increase on each status-signaling individual (that is, each individual with innate ability exceeding $\hat{w}$ ) is $\hat{z}$, then, indeed, the first term on the right-hand side of equation (16) captures the redistributive effect of a tax on contributions. This effect is positive and works in the direction of taxing "charitable" contributions, when the social welfare function exhibits a sufficiently large degree of inequality aversion. ${ }^{11}$

The second term, which also works in the direction of levying a tax on contributions, measures the corrective effect which offsets the wasteful statussignaling costs. To see this, fully differentiate the signaling constraint in (5) with

11 For instance, when the social planner is Rawlsian the second expression in the first set of brackets disappears and, clearly the re-distributive term is positive. Notably, in such a case, also the signaling correction term vanishes, as the contributors obtain zero weight in the social welfare measure. 
respect to $s$ at $s=0$, fixing the other tax parameters, $t$ and $T$, to obtain $\left.\frac{\partial \hat{\mathrm{z}}}{\partial s}\right|_{s=0}=-\hat{\mathrm{z}}$. Thus, a unit tax levied on contributions reduces the amount of contributions entailed by signaling by $\hat{z}$, thereby raising the utility derived by the individuals who engage in signaling, and consequently social welfare, by the corresponding expression in equation (16).

The last term captures the Pigouvian motive for subsidizing contributions. To see this, note first that the first-order condition for the optimal provision of the public good implies that:

$$
\left(\mu_{1}-\mu_{2}\right)=\alpha \cdot r^{\prime}(g) \cdot \int_{\underline{w}}^{\bar{w}} W^{\prime}[V(w)] d F(w)>0 .
$$

Because $-\hat{\mathrm{z}} \cdot[1-F(\hat{w})]$ is the effect of a unit tax on contributions on the total amount of public good, it follows that the third term measures indeed the gain in social welfare associated with the increase in public good provision generated by a unit subsidy granted to contributions. The third term is negative and works in the direction of granting a subsidy to contributions.

Note that the signaling correction term, which is the gain from a unit tax on contributions derived by the status-signaling individuals, is fully offset by the fact that each one of these individuals bears the tax on contributions. Hence, equation (16) reduces to:

(18) $\left.\quad \frac{\partial L}{\partial \mathrm{S}}\right|_{s=0, t^{*}, T^{*}, g^{*}, \hat{z}^{*}}=\mu_{1} \cdot \hat{z} \cdot[1-F(\hat{w})]-\left(\mu_{1}-\mu_{2}\right) \cdot \hat{z} \cdot[1-F(\hat{w})]$.

The interpretation of equation (18) is straightforward. A unit tax on contributions raises government revenues [and the transfer $(T)]$ by $\hat{z} \cdot[1-F(\hat{w})]$. But it also reduces total contributions for the public good by the same amount. Noting that $\mu_{1}$ is the 
social marginal benefit of the transfer $(T)$ and $\mu_{1}-\mu_{2}>0$ [see equation (17)] is the social marginal benefit of the public good $(g)$ completes the interpretation of equation (18). Naturally, equation (18) reduces to:

$$
\left.\frac{\partial L}{\partial s}\right|_{s=0, t^{*}, T^{*}, g^{*}, \hat{z}^{*}}=\mu_{2} \cdot \hat{z} \cdot[1-F(\hat{w})] \geq 0
$$

As explained above, a unit tax on contributions shifts resources at the amount of $\hat{\mathrm{Z}} \cdot[1-F(\hat{w})]$ from the public good provision $(g)$ to the uniform transfer $(T)$. The net marginal social benefit of this shift is indeed $\mu_{2} \cdot \hat{z} \cdot[1-F(\hat{w})]$, because $\mu_{2}$ is the difference between the marginal social benefit of the uniform transfer $\left(\mu_{1}\right)$ and the public good $\left(\mu_{1}-\mu_{2}\right)$. Note that the marginal social benefit of increasing $g$ cannot exceed that of increasing $T$, because $g$ is subject also to an additional constraint according to which it cannot fall short of the total amount of contributions. Thus, we establish:

Proposition 2: When contributions are purely driven by status seeking ( $\beta=1$ ), the optimal tax on contributions is non-negative.

Note that when the constraint in equation (11), which states that the government may not confiscate contributions and direct them towards its general budget [equation (10)], is binding, we may plausibly assume that the corresponding Lagrange multiplier $\left(\mu_{2}\right)$ is strictly positive. In this case, it is optimal to levy a positive tax on contributions. Naturally, this will be the case when the demand for the public good is sufficiently small (that is, when $\alpha$ is sufficiently small).

In contrast, when the demand for the public good is high enough (that is, when $\alpha$ is large enough), the constraint in equation (11) will not be binding. Hence, $\mu_{2}=0$, and it becomes optimal to set $s=0$. That is, it is not optimal for the government to 
directly affect contributions by either taxing or subsidizing them (through deduction or credits).

The rationale for these results is straightforward. When constraint (11) is binding $\left(\mu_{2}>0\right)$, there is an excess provision of public good. In this case, the government employs the tax on contributions in order to shift resources from public good provision towards redistribution. In contrast, when constraint (11) is not binding ( $\mu_{2}=0$ ), then the government is indifferent, at the margin, between allocating its revenues to the transfer $(T)$ or the public good $(g)$. Because a tax on contributions shifts resources from the public good to the transfer, there is no social gain or cost generated by such a tax. These results suggest that the reason for taxing status-driven contributions derives from the fact that the contributions themselves cannot be readily translated into redistribution, whereas the tax revenues can be. ${ }^{12}$

\section{Conclusions}

The conventional practice is to render a favorable tax treatment for charitable contributions, either through deductions or credits. The economic rationale for this practice is essentially Pigouvian: contributions for the financing of public goods generate a positive externality. In this paper, we point out that contributions may be also driven by a status-signaling motive. Therefore, as a pure signal, contributions generate also a negative externality. Moreover, contributions may be employed by the government in order to sort out the wealthy, and enhance redistribution.

Both considerations challenge the conventional practice. Naturally, whether and to what extent favorable tax treatment should be rendered to charitable contributions crucially depends on the relative strength of the altruistic motive vis-à-

\footnotetext{
${ }^{12}$ We thank an anonymous referee for this observation.
} 
vis the status-signaling one and on the desirability of the public goods financed by charity (the magnitude of the parameter $\alpha$ in our model).

The distinction between the conflicting tax implications of the two contributions motives raises the possibility of designing a system of differential tax treatment of contributions depending on whether they are anonymous or not. When contributions are anonymous, they indicate that they are driven by altruism. Therefore, a favorable tax treatment may be targeted toward the latter. Note further that the ability to signal status via 'charitable' contributions hinges crucially on the assumption that such contributions are indeed observable. The role of status-signaling in mitigating the free-rider problem may call for policy measures aimed at facilitating the dissemination of such information and rendering it more observable; see the related discussion of Cooter and Broughman (2005), suggesting a donation registry of the IRS via the internet. 


\section{Appendix A: Proof of Proposition 1}

We assume that second order conditions are satisfied, thus it suffices to show that there exists a marginal welfare gain by slightly decreasing the tax rate on charitable contributions from $s=0$. Differentiating the Lagrangean in (12) with respect to $t, T$ and $g$ yields the following first-order conditions (suppressing the tax parameters to abbreviate notation):

(A1)

$$
\left.\frac{\partial L}{\partial t}\right|_{s=0}=-\int_{\underline{w}}^{\bar{w}}\left[W^{\prime}[V(w)] \cdot \lambda(w) \cdot w \cdot[1-l(w)]\right] d F(w)-\mu_{1} \cdot t \cdot \int_{\underline{w}}^{\bar{w}}\left[w \cdot \frac{\partial l(w)}{\partial t}\right] d F(w)
$$

$$
\begin{array}{r}
+\mu_{1} \cdot \int_{\underline{w}}^{\bar{w}}[w \cdot[1-l(w)]] d F(w)+\left(\mu_{1}-\mu_{2}\right) \cdot \int_{\underline{w}}^{\bar{w}}\left[\frac{\partial z(w)}{\partial t}\right] d F(w)=0, \\
\left.\frac{\partial L}{\partial T}\right|_{s=0}=\int_{\underline{w}}^{\bar{w}}\left[W^{\prime}[V(w)] \cdot \lambda(w)\right] d F(w)-\mu_{1} \cdot t \cdot \int_{\underline{w}}^{\bar{w}}\left[w \cdot \frac{\partial l(w)}{\partial T}\right] d F(w)
\end{array}
$$

$$
+\left(\mu_{1}-\mu_{2}\right) \cdot \int_{\underline{w}}^{\bar{w}}\left[\frac{\partial z(w)}{\partial T}\right] d F(w)-\mu_{1}=0,
$$

$$
\left.\frac{\partial L}{\partial g}\right|_{s=0}=\alpha \cdot r^{\prime}(g) \cdot \int_{\underline{w}}^{\bar{w}}\left[W^{\prime}[V(w)]\right] d F(w)-\left(\mu_{1}-\mu_{2}\right)=0
$$

By virtue of the homotheticity assumption, one can write the optimal choice of an individual of ability $w$ as follows:

(A4) $z(w)=\delta \cdot[(1-t) \cdot w \cdot[1-l(w)]+T] /(1+s)$,

where $0<\delta<1$ and $\delta$ is independent of $w$.

Substituting for $z(w)$ from (A3) into (13), following some algebraic manipulations employing (A1) and (A2), and re-arranging, yields the following simplified form of the derivative in (13): 


$$
\begin{aligned}
\left.\frac{\partial L}{\partial s}\right|_{s=0}= & \mu_{1} \cdot \delta \cdot(1-t) \cdot t \cdot \int_{\underline{w}}^{\bar{w}}\left[w \cdot \frac{\partial l(w)}{\partial t}\right] d F(w)-\left(\mu_{1}-\mu_{2}\right) \cdot \delta \cdot(1-t) \cdot \int_{\underline{w}}^{\bar{w}}\left[\frac{\partial z(w)}{\partial t}\right] d F(w) \\
& -\mu_{1} \cdot \delta \cdot T \cdot t \cdot \int_{\underline{w}}^{\bar{w}}\left[w \cdot \frac{\partial l(w)}{\partial T}\right] d F(w)+\left(\mu_{1}-\mu_{2}\right) \cdot \delta \cdot T \cdot \int_{\underline{w}}^{\bar{w}}\left[\frac{\partial z(w)}{\partial T}\right] d F(w) \\
& -\mu_{1} \cdot t \cdot \int_{\underline{w}}^{\bar{w}}\left[w \cdot \frac{\partial l(w)}{\partial s}\right] d F(w)+\left(\mu_{1}-\mu_{2}\right) \cdot \int_{\underline{w}}^{\bar{w}}\left[\frac{\partial z(w)}{\partial s}\right] d F(w) .
\end{aligned}
$$

We need to prove that the sign of the derivative in (A5) is negative. We first turn to further simplify the expression on the right-hand side of (A5). Consider the following optimization problem, where an individual, given some labor/leisure choice, $l$, is choosing how to allocate the net income across consumption good, $c$, and charitable contribution, z. Formulating the Lagrangean yields:

$$
L(w, l, t, \tau, s) \equiv \max [u(c)+v(z)+v \cdot[(1-t) \cdot w \cdot(1-l)+T-c-(1+s) \cdot z]],
$$

where $v$ denotes the Lagrange multiplier. Now consider a small change in the tax system around the optimal linear labor income tax system (set for $s=0$ ), which is defined as follows: $d s=\Delta, d t=-\Delta \cdot \delta \cdot(1-t)$ and $d T=\Delta \cdot \delta \cdot T$, where $\Delta>0$ and is arbitrarily small. Fully differentiating the Lagrangean in (A6), using the envelope theorem, then yields:

$$
\left.d L\right|_{s=0, t, T}=\Delta \cdot v \cdot[-Z+\delta \cdot[(1-t) \cdot w \cdot(1-l)+T]]=0,
$$

where the last equality holds for any $l$, by virtue of the homotheticity [see (A4)] and the separability assumptions. It follows that the optimal labor/leisure choice of an individual of ability $w$ (for all $w$ ) is unaffected by the suggested small perturbation in the tax system around the optimum. Thus, for all $w$, it follows that:

(A8) $-\delta \cdot(1-t) \cdot \frac{\partial l(w)}{\partial t}+\frac{\partial l(w)}{\partial s}+\delta \cdot T \cdot \frac{\partial l(w)}{\partial T}=0$ 
Substitution into (A5) yields:

(A9)

$$
\begin{aligned}
\left.\frac{\partial L}{\partial s}\right|_{s=0}= & -\left(\mu_{1}-\mu_{2}\right) \cdot \delta \cdot(1-t) \cdot \int_{\underline{w}}^{\bar{w}}\left[\frac{\partial z(w)}{\partial t}\right] d F(w)+\left(\mu_{1}-\mu_{2}\right) \cdot \delta \cdot T \cdot \int_{\underline{w}}^{\bar{w}}\left[\frac{\partial z(w)}{\partial T}\right] d F(w) \\
& +\left(\mu_{1}-\mu_{2}\right) \cdot \int_{\underline{w}}^{\bar{w}}\left[\frac{\partial z(w)}{\partial s}\right] d F(w) .
\end{aligned}
$$

Consider next, the following optimization problem, where an individual, given some choice of the level of charitable contributions, $z$, is choosing the level of the consumption good, $c$, and leisure, $l$. Formulating the Lagrangean yields:

(A10) $L(w, z, t, \tau, s) \equiv \max [h(l)+u(c)+v \cdot[(1-t) \cdot w \cdot(1-l)+T-c-(1+s) \cdot z]]$, where $v$ denotes the Lagrange multiplier. Re-examining the effect of the small perturbation in the tax system around the optimum, by fully differentiating the Lagrangean in (A10), using the envelope theorem, yields:

(A11) $\left.d L\right|_{s=0, t, T}=\Delta \cdot v \cdot[-Z+\delta \cdot[(1-t) \cdot w \cdot(1-l)+T]]$.

Denote by $z^{*}(w)$, the optimal choice of the level of charitable contributions of the individual with ability $w$, given the optimal tax system. By construction of the optimal choice of the individual given the optimal tax system prior to the perturbation, it follows that:

(A12) $\frac{\partial v\left[z^{*}(w)\right]}{\partial z}+\left.\frac{\partial L\left[w, z^{*}(w)\right]}{\partial z}\right|_{s=0, t, T}=0$

After the perturbation, it follows, by virtue of (A11), that for any $z<z^{*}(w)$, $\left.d L\right|_{s=0, t, T}>0$; whereas, for any $z>z^{*}(w),\left.d L\right|_{s=0, t, T}<0$. Thus,

(A13) $\left.\frac{\partial L\left[w, z^{*}(w)\right]}{\partial z}\right|_{s=d s, t+d t, T+d T}<\left.\frac{\partial L\left[w, z^{*}(w)\right]}{\partial z}\right|_{s=0, t, T}$.

This implies that: 
(A14) $\frac{\partial v\left[z^{*}(w)\right]}{\partial z}+\left.\frac{\partial L\left[w, z^{*}(w)\right]}{\partial z}\right|_{s=d s, t+d t, T+d T}<0$.

Assuming that the second order conditions are satisfied, for any ability level, $w$, the individual is optimally reducing the level of charitable contributions in response to the suggested perturbation in the tax system. This implies that for every $w$,

(A15) $-\delta \cdot(1-t) \cdot \frac{\partial z(w)}{\partial t}+\frac{\partial z(w)}{\partial s}+\delta \cdot T \cdot \frac{\partial z(w)}{\partial T}<0$

Substituting into the right-hand side of (A9), recalling that by virtue of (A3) it follows that the term $\mu_{1}-\mu_{2}>0$, yields:

(A16) $\left.\frac{\partial L}{\partial s}\right|_{s=0}<0$

Thus, starting from a zero tax on charitable contributions, a small subsidy is socially desirable. This concludes the proof.

Note that when $\alpha \rightarrow 0$, the term $\left(\mu_{1}-\mu_{2}\right) \rightarrow 0$, by virtue of (A3), hence the optimal tax on charitable contributions converges to zero, due to the redundancy of commodity taxation. 


\section{Appendix B: Derivation of Equation 15}

Employing the envelope theorem, the effect of a small tax levied on contributions is given by the partial derivative of the Lagrangean in equation (14) evaluated at $s=0$ given the optimal levels of the set of control variables: $t, T, g$ and $\hat{z}$. Note that the (uniform) level of contribution in the pure status signaling case, $\hat{z}$, is chosen as a control variable in the optimization, as we incorporate the signaling constraint in equation (5) into the Lagrangean [the last expression on the right-hand side of equation (14)], so that its partial derivative with respect to $s$ is zero.

Differentiation yields thus the following expression:

$$
\begin{aligned}
\left.\frac{\partial L}{\partial s}\right|_{s=0} & =\int_{\underline{w}}^{\hat{w}}\left[W^{\prime}\left[V^{N S}(w)\right] \cdot \frac{\partial V^{N S}(w)}{\partial s}\right] d F(w)+\int_{\hat{w}}^{\bar{w}}\left[W^{\prime}\left[V^{S}(w)\right] \cdot \frac{\partial V^{S}(w)}{\partial s}\right] d F(w) \\
& -\mu_{1} \cdot t \cdot \int_{\underline{w}}^{\underline{w}}\left[w \frac{\partial l^{N S}(w)}{\partial s}\right] d F(w)-\mu_{1} \cdot t \cdot \int_{\hat{w}}^{\bar{w}}\left[w \frac{\partial l^{S}(w)}{\partial s}\right] d F(w)+\mu_{1} \cdot \hat{z} \cdot[1-F(\hat{w})]+ \\
& +\mu_{3}\left[\frac{\partial V^{S}(\hat{w})}{\partial s}-\frac{\partial V^{N S}(\hat{w})}{\partial s}\right] .
\end{aligned}
$$

In the pure status signaling case only individuals whose innate ability exceeds the threshold $\hat{w}$ choose to contribute (the amount of $\hat{z}$ ), whereas all other individuals set their contribution level at zero and are thus unaffected by the tax, s. Thus, it follows that $\frac{\partial V^{N S}(w)}{\partial s}=\frac{\partial l^{N S}(w)}{\partial s}=0$. By virtue of the individual optimization (employing the envelope theorem) it follows that $\frac{\partial V^{S}(w)}{\partial s}=-\lambda^{s}(w) \cdot \hat{z}$. Substitution into equation (B1) yields equation (15) in the main text. 


\section{Appendix C: Derivation of Equation 16}

We first re-formulate equation (15) in the main text for convenience.

$$
\begin{aligned}
\left.\frac{\partial L}{\partial s}\right|_{s=0, t^{*}, T^{*}, g^{*}, \hat{z}^{*}}= & -\hat{z} \cdot \int_{\hat{w}}^{\bar{w}}\left[W^{\prime}\left[V^{S}(w)\right] \cdot \lambda^{S}(w)\right] d F(w)-\mu_{1} \cdot t \cdot \int_{\hat{w}}^{\bar{w}}\left[w \cdot \frac{\partial I^{S}(w)}{\partial s}\right] d F(w) \\
& +\mu_{1} \cdot \hat{z} \cdot[1-F(\hat{w})]-\mu_{3} \cdot \lambda^{S}(\hat{w}) \cdot \hat{z}
\end{aligned}
$$

Differentiation of the Lagrangean in (14) with respect to $\hat{z}$ yields the following firstorder condition:

$$
\begin{aligned}
\left.\frac{\partial L}{\partial \hat{\mathbf{z}}}\right|_{s=0, t^{*}, T^{*}, g^{*}, \hat{z}^{*}}= & -\int_{\hat{w}}^{\bar{w}}\left[W^{\prime}\left[V^{s}(w)\right] \cdot \lambda^{S}(w)\right] d F(w)-\mu_{1} \cdot t \cdot \int_{\hat{w}}^{\bar{w}}\left[w \cdot \frac{\partial I^{S}(w)}{\partial \hat{z}}\right] d F(w) \\
& +\left(\mu_{1}-\mu_{2}\right) \cdot[1-F(\hat{w})]-\mu_{3} \cdot \lambda^{S}(\hat{w})=0 .
\end{aligned}
$$

Substituting for the term $\mu_{3} \cdot \lambda^{S}(\hat{w})$ from (C2) into (C1) yields:

$$
\begin{aligned}
\left.\frac{\partial L}{\partial s}\right|_{s=0, t^{*}, T^{*}, y^{*}, \hat{z}^{*}}= & \mu_{1} \cdot \hat{\mathrm{z}} \cdot[1-F(\hat{w})]-\hat{z} \cdot \int_{\hat{w}}^{\bar{w}}\left[W^{\prime}\left[V^{s}(w)\right] \cdot \lambda^{s}(w)\right] d F(w) \\
& -\mu_{1} \cdot t \cdot \int_{\hat{w}}^{\bar{w}}\left[w \cdot \frac{\partial l^{s}(w)}{\partial s}\right] d F(w)+\mu_{1} \cdot t \cdot \hat{z} \int_{\hat{w}}^{\bar{w}}\left[w \cdot \frac{\partial l^{s}(w)}{\partial \hat{z}}\right] d F(w) \\
& +\hat{z} \cdot \int_{\hat{w}}^{\bar{w}}\left[W^{\prime}\left[V^{S}(w)\right] \cdot \lambda^{s}(w)\right] d F(w)-\left(\mu_{1}-\mu_{2}\right) \cdot \hat{\mathbf{z}} \cdot[1-F(\hat{w})] .
\end{aligned}
$$

Re-formulating the budget constraint faced by an individual who engages in signaling yields:

$$
J(l, c, t, T, s, \hat{z}) \equiv(1-t) \cdot w \cdot(1-l)+T-c-(1+s) \cdot \hat{z}=0
$$

Differentiation of the expression in (C4) yields:

(C5) $\left.\quad \hat{z} \cdot \frac{\partial J}{\partial \hat{\mathbf{Z}}}\right|_{s=0}-\left.\frac{\partial J}{\partial s}\right|_{s=0}=0$.

Thus, for any ability level $w$, the following holds: 
(C6) $\left.\hat{z} \cdot \frac{\partial l^{s}}{\partial \hat{z}}\right|_{s=0}-\left.\frac{\partial l^{s}}{\partial s}\right|_{s=0}=0$.

Substituting into (C3) yields equation (16) in the main text. This completes the derivation. 


\section{References}

Akerlof, G. (1978). "The Economics of Tagging as Applied to the Optimal Income Tax," American Economic Review, 68, 8-19.

Andreoni, J. (1989) "Giving with Impure Altruism: Applications to Charity and Ricardian Equivalence", Journal of Political Economy, 97, 1447-1458

Andreoni, J. (1990) "Impure Altruism and Donation to Public Goods: A Theory of Warm-Glow Giving", Economic Journal, 100, 464-477

Bergstrom, T., L. Blume and H. Varian (1986) "On the Private Provision of Public Goods", Journal of Public Economics, 29, 25-49

Boskin, M. and E. Sheshinski (1978) "Optimal Redistributive Taxation when Individual Welfare Depends upon Relative Income", Quarterly Journal of Economics, 92, 589-601

Cooter, R. and B. Broughman (2005) "Charity, Publicity and the Donation Registry", The Economists' Voice, Volume 2, Issue 3, The Berkeley Electronic Press

Deaton, A. (1979) "Optimally Uniform Commodity Taxes", Economics Letters, 2, $357-361$

De-Botton, A. (2005) "Status Anxiety", Penguin Books

Diamond, P. (2006) "Optimal Tax Treatment of Private Contributions for Public Goods with and without Warm Glow Preferences", Journal of Public Economics, 90, 897-919

Frank, R. (1984a) "Interdependent Preferences and the Competitive Wage Structure", Rand Journal of Economics, 15, 510-520

Frank, R. (1984b) "Are Workers Paid Their Marginal Products?", American Economic Review, 74, 549-571 
Frank, R. (1985a) "The Demand for Unobservable and Other Non-positional Goods", American Economic Review, 75, 101-116

Frank, R. (1985b) "Choosing the Right Pond, Human Behavior and the Quest for Status", Oxford University Press, Oxford

Glazer, A. and K. Konrad (1996) "A Signaling Explanation for Charity", American Economic Review, 86, 1019-1028

Green, J. and J-J. Laffont (1979) "Individual Incentives in Public Decision-Making", North-Holland, Amsterdam

Harbaugh, W. (1998a) "What Do Donations Buy? A Model of Philanthropy Based on Prestige and Warm Glow", Journal of Public Economics, 67, 269-284

Harbaugh, W. (1998b) "The Prestige Motive for Making Charitable Transfers", American Economic Review, 88, 277-282

Hirsch, F. (1976) "Social Limits to Growth", Harvard University Press, Cambridge Ireland, N. (1994) "On Limiting the Market for Status Signals", Journal of Public Economics, 53, 91-110

Ireland, N. (1998) "Status Seeking, Income Taxation and Efficiency", Journal of Public Economics, 70, 99-113

Ireland, N. (2001) "Optimal Income Tax in the Presence of Status Effects", Journal of Public Economics, 81, 193-212

Mirrlees, J. (1971) "An Exploration in the Theory of Optimum Income Taxation", Review of Economic Studies, 38, 175-208 


\section{CESifo Working Paper Series}

(for full list see www.cesifo-group.de)

1840 Erkki Koskela and Mikko Puhakka, Stability and Dynamics in an Overlapping Generations Economy under Flexible Wage Negotiation and Capital Accumulation, November 2006

1841 Thiess Buettner, Michael Overesch, Ulrich Schreiber and Georg Wamser, Taxation and Capital Structure Choice - Evidence from a Panel of German Multinationals, November 2006

1842 Guglielmo Maria Caporale and Alexandros Kontonikas, The Euro and Inflation Uncertainty in the European Monetary Union, November 2006

1843 Jan K. Brueckner and Ann G. Largey, Social Interaction and Urban Sprawl, November 2006

1844 Eytan Sheshinski, Differentiated Annuities in a Pooling Equilibrium, November 2006

1845 Marc Suhrcke and Dieter Urban, Are Cardiovascular Diseases Bad for Economic Growth?, November 2006

1846 Sam Bucovetsky and Andreas Haufler, Preferential Tax Regimes with Asymmetric Countries, November 2006

1847 Luca Anderlini, Leonardo Felli and Andrew Postlewaite, Should Courts always Enforce what Contracting Parties Write?, November 2006

1848 Katharina Sailer, Searching the eBay Marketplace, November 2006

1849 Paul De Grauwe and Pablo Rovira Kaltwasser, A Behavioral Finance Model of the Exchange Rate with Many Forecasting Rules, November 2006

1850 Doina Maria Radulescu and Michael Stimmelmayr, ACE vs. CBIT: Which is Better for Investment and Welfare?, November 2006

1851 Guglielmo Maria Caporale and Mario Cerrato, Black Market and Official Exchange Rates: Long-Run Equilibrium and Short-Run Dynamics, November 2006

1852 Luca Anderlini, Leonardo Felli and Andrew Postlewaite, Active Courts and Menu Contracts, November 2006

1853 Andreas Haufler, Alexander Klemm and Guttorm Schjelderup, Economic Integration and Redistributive Taxation: A Simple Model with Ambiguous Results, November 2006

1854 S. Brock Blomberg, Thomas DeLeire and Gregory D. Hess, The (After) Life-Cycle Theory of Religious Contributions, November 2006 
1855 Albert Solé-Ollé and Pilar Sorribas-Navarro, The Effects of Partisan Alignment on the Allocation of Intergovernmental Transfers. Differences-in-Differences Estimates for Spain, November 2006

1856 Biswa N. Bhattacharyay, Understanding the Latest Wave and Future Shape of Regional Trade and Cooperation Agreements in Asia, November 2006

1857 Matz Dahlberg, Eva Mörk, Jørn Rattsø and Hanna Ågren, Using a Discontinuous Grant to Identify the Effect of Grants on Local Taxes and Spending, November 2006

1858 Ernesto Crivelli and Klaas Staal, Size and Soft Budget Constraints, November 2006

1859 Jens Brøchner, Jesper Jensen, Patrik Svensson and Peter Birch Sørensen, The Dilemmas of Tax Coordination in the Enlarged European Union, November 2006

1860 Marcel Gérard, Reforming the Taxation of Multijurisdictional Enterprises in Europe, "Coopetition" in a Bottom-up Federation, November 2006

1861 Frank Blasch and Alfons J. Weichenrieder, When Taxation Changes the Course of the Year - Fiscal Year Adjustments and the German Tax Reform 2000/2001, November 2006

1862 Hans Jarle Kind, Tore Nilssen and Lars Sørgard, Competition for Viewers and Advertisers in a TV Oligopoly, November 2006

1863 Bart Cockx, Stéphane Robin and Christian Goebel, Income Support Policies for PartTime Workers: A Stepping-Stone to Regular Jobs? An Application to Young LongTerm Unemployed Women in Belgium, December 2006

1864 Sascha O. Becker and Marc-Andreas Muendler, The Effect of FDI on Job Separation, December 2006

1865 Christos Kotsogiannis and Robert Schwager, Fiscal Equalization and Yardstick Competition, December 2006

1866 Mikael Carlsson, Stefan Eriksson and Nils Gottfries, Testing Theories of Job Creation: Does Supply Create Its Own Demand?, December 2006

1867 Jacques H. Drèze, Charles Figuières and Jean Hindriks, Voluntary Matching Grants Can Forestall Social Dumping, December 2006

1868 Thomas Eichner and Marco Runkel, Corporate Income Taxation of Multinationals and Unemployment, December 2006

1869 Balázs Égert, Central Bank Interventions, Communication and Interest Rate Policy in Emerging European Economies, December 2006

1870 John Geweke, Joel Horowitz and M. Hashem Pesaran, Econometrics: A Bird's Eye View, December 2006 
1871 Hans Jarle Kind, Marko Koethenbuerger and Guttorm Schjelderup, Taxation in TwoSided Markets, December 2006

1872 Hans Gersbach and Bernhard Pachl, Cake Division by Majority Decision, December 2006

1873 Gunther Schnabl, The Evolution of the East Asian Currency Baskets - Still Undisclosed and Changing, December 2006

1874 Horst Raff and Michael J. Ryan, Firm-Specific Characteristics and the Timing of Foreign Direct Investment Projects, December 2006

1875 Jukka Pirttilä and Håkan Selin, How Successful is the Dual Income Tax? Evidence from the Finnish Tax Reform of 1993, December 2006

1876 Agnieszka Stążka, Sources of Real Exchange Rate Fluctuations in Central and Eastern Europe - Temporary or Permanent?, December 2006

1877 Xavier Calsamiglia, Teresa Garcia-Milà and Therese J. McGuire, Why do Differences in the Degree of Fiscal Decentralization Endure?, December 2006

1878 Natacha Gilson, How to be Well Shod to Absorb Shocks? Shock Synchronization and Joining the Euro Zone, December 2006

1879 Scott Alan Carson, Modern Health Standards for Peoples of the Past: Biological Conditions by Race in the American South, 1873 - 1919, December 2006

1880 Peter Huber, Michael Pfaffermayr and Yvonne Wolfmayr, Are there Border Effects in the EU Wage Function?, December 2006

1881 Harry Flam and Håkan Nordström, Euro Effects on the Intensive and Extensive Margins of Trade, December 2006

1882 Panu Poutvaara and Mikael Priks, Hooliganism in the Shadow of the 9/11 Terrorist Attack and the Tsunami: Do Police Reduce Group Violence?, December 2006

1883 Ruud A. de Mooij and Gaëtan Nicodème, Corporate Tax Policy, Entrepreneurship and Incorporation in the EU, December 2006

1884 Johannes Becker and Clemens Fuest, Corporate Tax Policy and International Mergers and Acquisitions - Is the Tax Exemption System Superior?, January 2007

1885 Momi Dahan and Udi Nisan, The Effect of Benefits Level on Take-up Rates: Evidence from a Natural Experiment, January 2007

1886 José García-Solanes, Francisco I. Sancho-Portero and Fernando Torrejón-Flores, Beyond the Salassa-Samuelson Effect in some New Member States of the European Union, January 2007 
1887 Peter Egger, Wolfgang Eggert and Hannes Winner, Saving Taxes Through Foreign Plant Ownership, January 2007

1888 Timothy J. Goodspeed and Andrew Haughwout, On the Optimal Design of Disaster Insurance in a Federation, January 2007

1889 Wim Groot, Henriëtte Maassen van den Brink and Bernard van Praag, The Compensating Income Variation of Social Capital, January 2007

1890 Bas Jacobs, Ruud A. de Mooij and Kees Folmer, Analyzing a Flat Income Tax in the Netherlands, January 2007

1891 Hans Jarle Kind, Guttorm Schjelderup and Frank Stähler, Newspapers and Advertising: The Effects of Ad-Valorem Taxation under Duopoly, January 2007

1892 Erkki Koskela and Rune Stenbacka, Equilibrium Unemployment with Outsourcing under Labour Market Imperfections, January 2007

1893 Maarten Bosker, Steven Brakman, Harry Garretsen, Herman de Jong and Marc Schramm, The Development of Cities in Italy 1300 - 1861, January 2007

1894 Michel Beine, Oscar Bernal, Jean-Yves Gnabo and Christelle Lecourt, Intervention Policy of the BoJ: A Unified Approach, January 2007

1895 Robert S. Chirinko and Daniel J. Wilson, State Investment Tax Incentives: A Zero-Sum Game?, January 2007

1896 Theo S. Eicher and Oliver Roehn, Sources of the German Productivity Demise Tracing the Effects of Industry-Level ICT Investment, January 2007

1897 Helge Berger, Volker Nitsch and Tonny Lybek, Central Bank Boards around the World: Why does Membership Size Differ?, January 2007

1898 Gabriel Felbermayr and Wilhelm Kohler, Does WTO Membership Make a Difference at the Extensive Margin of World Trade?, January 2007

1899 Benno Torgler and Friedrich Schneider, The Impact of Tax Morale and Institutional Quality on the Shadow Economy, January 2007

1900 Tomer Blumkin and Efraim Sadka, On the Desirability of Taxing Charitable Contributions, January 2007 